\title{
Processing a dynamic odor in a noisy chemical environment
}

\author{
Jeffrey A Riffell \\ From 1st International Workshop on Odor Spaces \\ Hannover, Germany. 4-7 September 2013
}

Natural, behaviorally significant olfactory stimuli typically are mixtures of volatiles whose concentrations co-vary dynamically in time and space. The olfactory world is also an arena of constant movement and flux. Once emitted by a source, volatiles are dispersed and mixed by the ambient motion of air to form a shifting and filamentous plume. How does the olfactory system quickly discriminate the fluctuating signal from a background? Here in this presentation, I briefly discuss our use of new analytical technologies that permit simultaneous measurement of multiple volatiles at timescales equivalent to (1) the turbulent aerodynamic regimes that advect and mix the scents, and (2) olfactory processing and behavior in both invertebrate and vertebrates. Using proton-transfer-reaction mass spectrometry, the fluctuating odor plume from a natural odor source - the $D$. wrightii flower, an important hostplant for Manduca sexta moths - was characterized in the field. Results from these measurements demonstrated that, even within the headspace of the flower, the ion plume was highly dynamic in both time and space. Moreover, $1 \mathrm{~m}$ away from the source the chemical background became mixed with the odor plume, thus causing significant modification of the ratio of odorants in the plume.

How does changing the ratio of constituents alter the processing of the odor and behavior? We first examined the ability of the moths to encode the temporally dynamic signal in the complex background by multi-channel recording in the moth's antennal (olfactory) lobe (AL). Our results show that the neural ensemble tracked the odor at temporal frequencies up to $5 \mathrm{~Hz}$. However, when the odor was embedded in a chemical background, the ensemble representation of the odor was significantly altered. Moreover, the change in AL representation was due to the altering the balance of excitation and inhibition in the system. Finally, behavioral experiments showed that

Department of Biology, University of Washington, Seattle, WA, USA the ability to navigate in a plume significantly decreased when background odors of increasing similarity to the floral mixtures were presented. Together, these results (1) demonstrate the effectiveness of new analytical technologies for characterizing the natural olfactory environment; (2) the composition of the plume can be significantly altered at short time- and spacial-scales; (3) provide new evidence that odor navigation is mediated by the precise integration of multiple glomerular pathways, and (4) alteration of the odor input transforms the network representations.

Published: 16 April 2014

doi:10.1186/2044-7248-3-S1-O28

Cite this article as: Riffell: Processing a dynamic odor in a noisy

chemical environment. Flavour 2014 3(Suppl 1):O28.

Submit your next manuscript to BioMed Central and take full advantage of:

- Convenient online submission

- Thorough peer review

- No space constraints or color figure charges

- Immediate publication on acceptance

- Inclusion in PubMed, CAS, Scopus and Google Scholar

- Research which is freely available for redistribution 